\title{
Time of parturition in rats after melatonin administration or change of photoperiod
}

\author{
M. J. Bosc \\ Station de Physiologie de la Reproduction, Institut National de la Recherche Agronomique, \\ 37380 Monnaie, France
}

\begin{abstract}
Summary. Two experiments were carried out with rats isolated at mating (Day 1 of gestation) and kept in a standard light regimen of $14 \mathrm{~h}$ light (14L:10D). All treatments started on Day 8 of gestation; periodicities of $23: 45 \mathrm{~h}, 24: 00 \mathrm{~h}$ and $24: 15 \mathrm{~h}$ were applied to the light phase (14L) in Exp. I and to daily treatment with melatonin $(0.3 \mathrm{mg} / \mathrm{rat})$ or its vehicle in Exp. II. In Exp. II, the animals were placed in a continuous dim light regimen and injections were given at a time corresponding to lights off. In all groups, rats delivered on the afternoon of Day 22 and on the morning of Day 23 after a cessation of parturitions. The rates of births during these two times depended on the periodicities of the light phase or those of melatonin administration. With a periodicity of $24: 15 \mathrm{~h}, 85.7 \%$ of rats in Exp. I and $85.7 \%$ of rats in Exp. II delivered on Day 22 . With a periodicity of $23: 45 \mathrm{~h}, 83.0 \%$ of births occurred on Day 23 in Exp. I and $57.7 \%$ in Exp. II with melatonin instead of $25.9 \%$ in the corresponding vehicle controls. These results suggest that melatonin secretion may be a mechanism whereby photoperiod regulates the time of parturition in the rat.
\end{abstract}

\section{Introduction}

Photoperiod regulates the time of birth in rats (Bosc, 1981) and the signal may be via melatonin to coordinate reproductive events with the changes in lighting conditions (Tamarkin et al., 1985). Although early studies suggest that the pineal gland and melatonin are not involved in parturition in this species (Mitchell \& Yochim, 1970; Nir \& Hirschmann, 1980, 1982), such a conclusion would be premature for several reasons. In the rat, birth either precedes the main daily physical activity or follows it depending upon the environmental conditions (Bosc et al., 1986). Melatonin is able to entrain the rest-activity cycle in this species (Armstrong \& Redman, 1985) and this may contribute indirectly or directly to birth timing. Luteinizing hormone ( $\mathrm{LH})$ is able to induce a fall of plasma progesterone leading to premature parturition in late pregnant rats (Gordon \& Sherwood, 1982). Observations (Tigghelaar \& Nalbandov, 1975; Nir \& Hirschmann, 1980) on LH concentrations in pituitary and serum of intact or pinealectomized pregnant rats, treated or not with melatonin, support another possible mode of action. Adrenalectomy of the mothers alters the time of birth in response to different photoperiods (Bosc \& Nicolle, 1980) and complex relationships between pineal, melatonin and adrenal functions may also be implicated. Melatonin affects steroidogenesis in the adrenals (Ogle \& Kitay, 1978) and accelerates the re-entrainment of the circadian adrenocortical rhythm (Murakami et al., 1983). Inversely, glucocorticosteroids are involved in the down regulation of cyclic AMP (Daya \& Joubert, 1984) and in the metabolism of hydroxyindole-O-methyl-transferase (Wong et al., 1985) in the rat pineal.

In view of these observations, it was clearly of interest to evaluate the efficiency of melatonin in modifying time of parturition using different paradigms. Two successive experiments were carried out to compare the entrainment of birth by opposite light-dark cycles with the effects of daily melatonin administration in the absence of a photoperiodic cue. 


\section{Materials and Methods}

Rats of Wistar origin (strain 03 of our colony) were kept at a constant temperature $\left(20^{\circ} \mathrm{C}\right)$ under cool white fluorescent lighting. The standard light regimen was $14 \mathrm{~h}$ light and $10 \mathrm{~h}$ darkness (14L:10D) with lights on from 06:00 $\mathrm{h}$ to $20: 00 \mathrm{~h}$ (local time). After 3 months of age, the females were caged with males for 3 consecutive days. Mating (Day 1 of pregnancy) was assessed by the presence of spermatozoa in vaginal smears taken in the morning and mated females were isolated (one/box) and allocated to an experimental group. Each group was completed in 2 or 3 mating sessions, and each female was allowed a maximum of 2 pregnancies. Food and water were available ad libitum, and were renewed two or three times a week, during the light phase.

Experiment I. Three groups were formed with 173 pregnant rats. The 64 control rats (Group C) were kept under the standard light regimen (14L:10D). From Day 8 of gestation, the other rats were exposed to a daily shift of light phase, the duration of which remained unchanged $(14 \mathrm{~L})$ : in Group $\mathrm{BC}(\mathrm{N}=53)$, the light phase was advanced by $15 \mathrm{~min}$ daily, and in Group FC $(\mathrm{N}=56)$ it was delayed by $15 \mathrm{~min}$, and so the periods of lights on and lights off were 23:45 $\mathrm{h}$ and 24:15 h respectively. Under these conditions, light was given, on Day 23 of gestation, between 02:00 and 16:00 $\mathrm{h}$ in Group BC and between 10:00 and 02:00 $\mathrm{h}$ in Group FC.

Experiment II. Eight groups were formed using 177 pregnant rats. A control group $(\mathrm{C} ; \mathrm{N}=20)$ was kept in the 14L:10D regimen. The other rats were exposed to this regimen until Day 8 and then they were put into continuous dim light. This was achieved by placing an opaque shade around the light source in such a way as to produce an indirect illumination of the animals by reflection from the white walls and roof of the room. The shade was adjusted just before lights off on Day 7 of gestation. Luminosity was checked (Luxmètre CL 2010, Chauvin \& Arnoux, Paris) at the beginning of this lighting regimen and at the end of gestation; according to the position of each box in the room, 0.2-1.1 lux was obtained at the levels of the animals instead of 100-300 lux under our usual conditions. In Group LL $(\mathrm{N}=22)$, rats were kept under these conditions without further treatment. In the other 6 groups, rats received a daily subcutaneous injection of $0.3 \mathrm{mg}$ melatonin (in $0.5 \mathrm{ml}$ of a working solution) or the solvent $(0.5 \mathrm{ml})$. In Groups V $(\mathrm{N}=20)$ and $M(\mathrm{~N}=29)$, the solvent or melatonin was given at a time corresponding to lights off under the standard light regimen (20:00 h). In Groups $F V(N=19)$ and $F M(N=14)$, the solvent or melatonin was given with a periodicity of 24:15 h (corresponding to Group FC in Exp. I) and the administration started at 20:15 h on Day 8 and finished at 23:30 h on Day 21. In Groups BV $(N=27)$ and $B M(N=26)$ the solvent and melatonin were given with a periodicity of 23:45 h (corresponding to Group BC in Exp. I); the administration started at 19:45 h on Day 8 and ended at 16:30 h on Day 21. Paired experiments with Groups V and M, FV and FM, BV and BM, were conducted in parallel in separate rooms. In each room, the treatment was given in a fixed order (including a permutation between vehicle and treatment) to maintain the shift of $15 \mathrm{~min}$ per day for each rat. All treatments were stopped on Day 21 of gestation, 1 day before the first expected births, to avoid manipulation just before birth since stress at that time may affect both the timing and duration of expulsion of young (Bosc \& Nicolle, 1979). Melatonin (Sigma, P.O. Box 14508, St Louis, MO, U.S.A.) was dissolved in pure ethanol $(60 \mathrm{mg} / \mathrm{ml})$ (stock solution) and stored at $-20^{\circ} \mathrm{C}$; every day a working solution was made containing $1 \%$ ethanol with the stock solution and sterile pyrogen-free physiological saline.

To perform the injections at convenient hours, all rats used in this experiment were put under an altered standard photoperiod with lights on from 00:00 to 14:00 h. The first sessions of mating occurred 6 weeks later. As the controls showed the same birth distributions with respect to the light regimen as the corresponding group in Exp. I or others (Bosc, 1981), all hours were converted into the usual local times; the experimental procedures as well as the results are presented in this way.

Observations and analysis. Observations were performed as previously described (Bosc \& Nicolle, 1980). From Day 22, the rats were checked every $2 \mathrm{~h}$ in Exp. I and every hour in Exp. II. The hour preceding the observation of the first young was considered to be the time of birth. Birth rates on Days 22 and 23 of gestation were then compared $\left(\chi^{2}\right.$ analysis; Vessereau, 1960); the interval between birth and a given reference point was also taken into account (analysis of variance; Vessereau, 1960). In each experiment, the homogeneity of the groups was assessed on the basis of litter size, stillbirth rate and birth weight of live young (weight taken $2-6 \mathrm{~h}$ after the end of parturition).

\section{Results}

\section{Experiment $I$}

The three groups were homogeneous $(P>0.05)$ for litter sizes (mean \pm s.d., $10 \cdot 1 \pm 3 \cdot 4)$, stillbirth rates (mean $5 \cdot 8 \%$, range $5 \cdot 2-6 \cdot 1 \%$ ) and the percentage of mothers with stillborn young (mean $28.9 \%$, range $28.3-29 \cdot 7 \%$ ). In each group, parturitions were split into two distinct periods separated by a time without births corresponding to the dark phase common to Days 22 and 23 of pregnancy (Fig. 1). In Group C, $59.4 \%$ of the rats delivered during the first period and $40.6 \%$ in the second; these percentages were respectively 85.7 and $14.3 \%$ in Group $\mathrm{FC}$, and $17 \cdot 3$ and $82.7 \%$ in Group BC. This last group differed from Group FC $(P<0.001)$ and Group C $(P<0.001)$, and Group FC differed also from Group C $(P<0.01)$. 


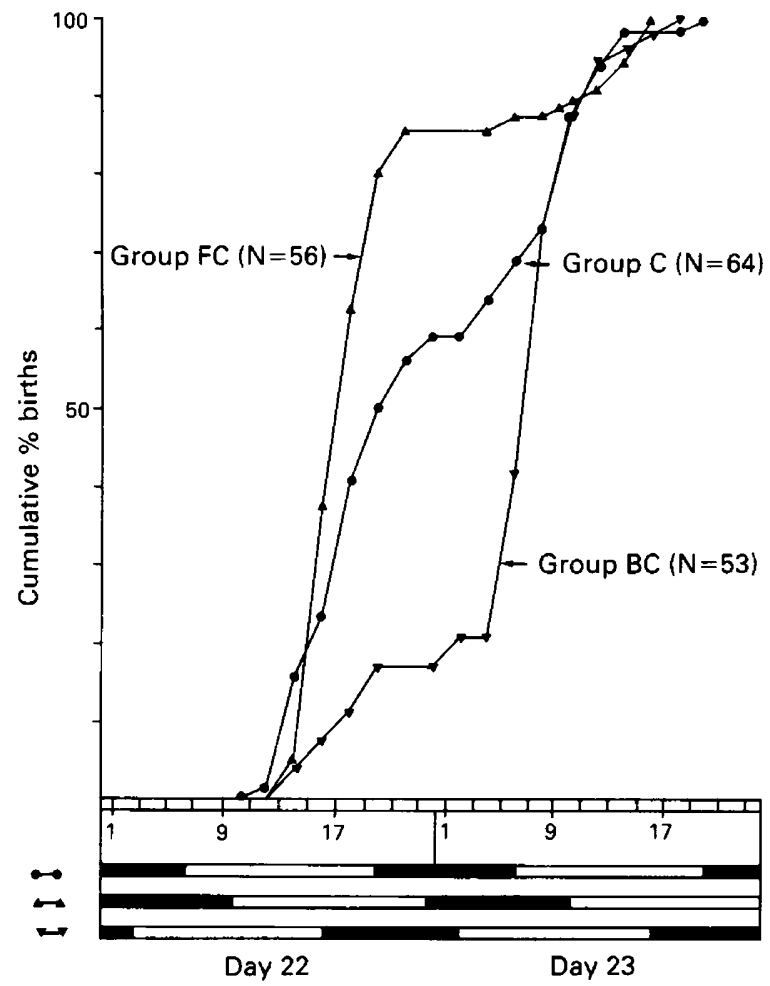

Fig. 1. Birth distributions on Days 22 and 23 of gestation in rats placed, during Exp. I, in one of 3 light regimens: a standard photoperiod, 14L:10D (Group C) or a $15 \mathrm{~min}$ daily shift of light phase (14L) corresponding to periodicities of $23: 45 \mathrm{~h}$ (Group BC) and $24: 15 \mathrm{~h}$ (Group FC). The positions of the light phases are represented (bottom) for the last 2 days of gestation.

In the three groups, the first period of birth was observed over the same hours on Day 22 of gestation; parturition began at about $12: 00 \mathrm{~h}$ (local time) and the mean times were not different $(P>0.05)$ as judged by the intervals between Day 22, 00:00 h, and parturitions occurring during the following $24 \mathrm{~h}$ (mean \pm s.d., 17:40 \pm 3:00 h, 17:40 $\pm 2: 00 \mathrm{~h}$ and 17:19 $\pm 2: 27 \mathrm{~h}$ in Groups C, $\mathrm{FC}$ and $\mathrm{BC}$ respectively). By comparison, the second period occurred at different times on Day 23 and the mean intervals between Day $23,00: 00 \mathrm{~h}$, and the following births differed among the groups (mean \pm s.d., 9:21 \pm 3:00 h, 13:00 $\pm 3: 30 \mathrm{~h}$ and 8:27 \pm 3:00 $\mathrm{h}$ in Groups C, FC and BC respectively; $P<0.01$ ).

\section{Experiment II}

The 8 groups were homogeneous $(P>0 \cdot 05)$ for litter sizes (mean \pm s.d., $10 \cdot 1 \pm 2 \cdot 8)$, stillbirth rates (mean $4 \cdot 2 \%$, range $2 \cdot 8-5 \cdot 1 \%$ ), the percentage of females with stillborn young (mean 28.8 , range $20 \cdot 0-37 \cdot 0 \%$ ) and the birth weight of live young (mean \pm s.d., $5 \cdot 8 \pm 0.5 \mathrm{~g}$ ).

As observed in Exp. I, the rats in Group $C$ had two periods of birth: $55.0 \%$ of the rats delivered during the second half of the light phase on Day 22 of gestation and $45.0 \%$ after lights on on Day 23 and the nocturnal cessation in parturitions was very marked in this group (Fig. 2a). By comparison, the percentage of deliveries on Days 22 and 23 was different in Group LL $(P<0.025): 86.4 \%$ of births were clustered in the first period observed on Day 22 and the rest $(13.6 \%)$ were seen on Day 23 after a break apparently shorter than that in Group C (Fig. 2a). In Groups V, BV and FV, 


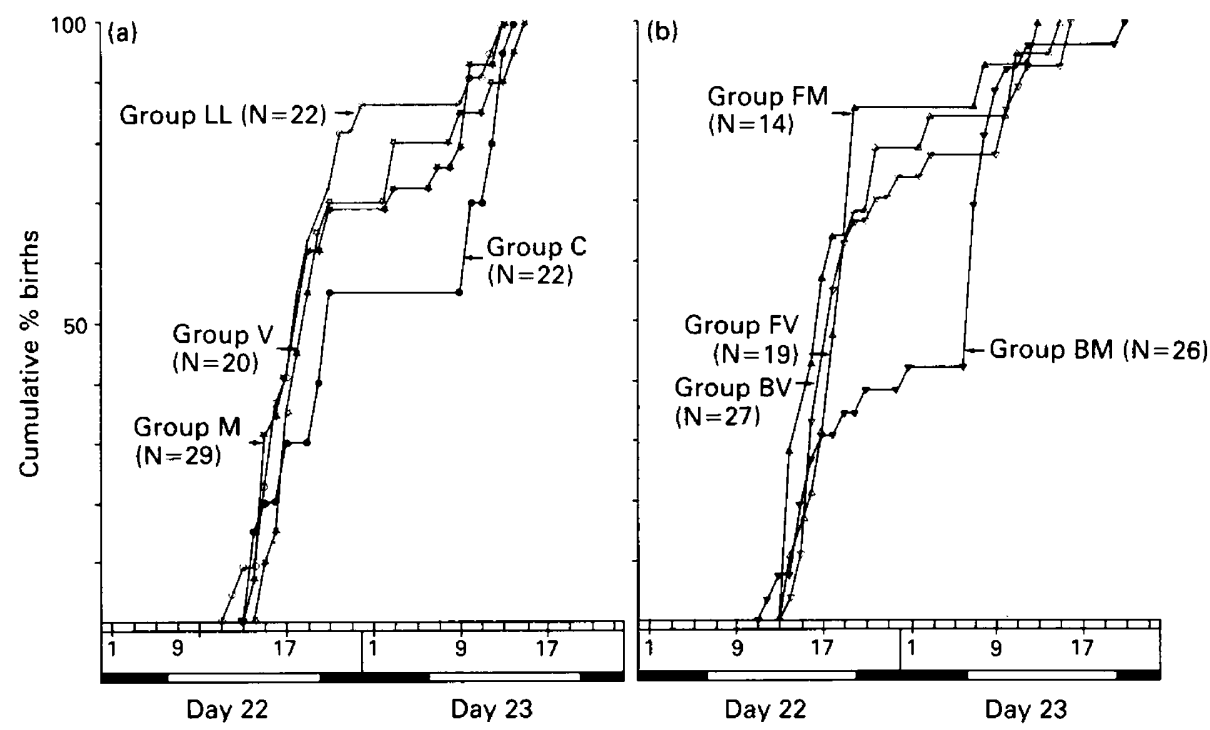

Fig. 2. Birth distributions on Days 22 and 23 of gestation in rats placed, during Exp. II, under a standard photoperiod (Group C) (shown at bottom of panels) or under a continuous dim light regimen from Day 8 (Groups $L L, V, M, B V, B M, F V$ and $F M)$. In (a), the vehicle and melatonin $(0.3 \mathrm{mg})$ were given daily to Groups $V$ and $M$ respectively at the same hour $(20: 00 \mathrm{~h}$; periodicity of 24:00 h) from Day 8 until Day 21. In Group LL, the rats were untreated. In (b), the rats received daily the vehicle (Groups BV and FV) or $0.3 \mathrm{mg}$ melatonin (Groups BM and FM) from Day 8 until Day 21. In Groups BV and BM, treatments started at 19:45 h on Day 8 and were continued with a periodicity of $23: 45 \mathrm{~h}$. In Groups FV and FM, treatments started at $20: 15 \mathrm{~h}$ on Day 8 and were continued with a periodicity of $24: 15 \mathrm{~h}$.

the distributions of births followed a pattern similar to that as seen in Group LL $(P>0.05)$ (Fig. $2 \mathrm{a}, 2 \mathrm{~b})$. In Groups $M$ and FM, the rates of births observed on Days 22 and 23 were similar to those of their corresponding vehicle controls, Groups V and FV $(P>0.05)$. Therefore 70.0 and $69.0 \%$ of parturitions were seen on Day 22 in Groups $V$ and $M$ respectively and 78.9 and $85.7 \%$ in Groups FV and FM (Fig. 2a, 2b). In contrast, $42.3 \%$ of rats receiving melatonin with a periodicity of 23 : $45 \mathrm{~h}$ (Group BM) gave birth during the first period located on Day 22 and $57 \cdot 7 \%$ on Day 23 instead of 74.1 and $25.9 \%$ respectively in Group BV $(P<0.025)$.

When the births observed during the first period were taken into account, the intervals between Day $22,00: 00 \mathrm{~h}$, and birth were not different $(P>0.05)$; they averaged 16:38 $\mathrm{h}( \pm 3: 00 \mathrm{~h})$. This indicated that the first period of births was spread over the same hours and began at about 12:00 $\mathrm{h}$ (Fig. 2a, 2b) as in Exp. I (Fig. 1). However, rats of Groups M and FM tended to deliver earlier than their respective control rats (on average 1:05 h for Groups $\mathbf{M}$ and FM compared with Groups V and FV; $P>0.05$ ). In view of the limited number of parturitions observed on Day 23, it was difficult to locate the period of birth on that day in all groups by the analysis of intervals between Day 23, 00:00 h, and birth. In Groups $\mathrm{V}$ and $\mathrm{M}$, these intervals averaged 8:20 $\mathrm{h}(P>0.05)$; they were greater in Groups $\mathrm{C}$ and $\mathrm{BV}(10: 50 \mathrm{~h}$ and 10:10 h respectively) and were less in Group BM than in Group C (7:55 $\pm 3: 35 \mathrm{~h}$ vs 10:50 $\pm 1: 30 \mathrm{~h})(P<0.05)$.

\section{Discussion}

These results indicate that exogenous melatonin can modify the time of birth in the rat in a manner analogous to that of photoperiod manipulation. The differences in the distribution of parturitions 
following the three periodicities of melatonin administration also demonstrate that the efficacy of melatonin depends on the timing of its administration, as already underlined for other reproductive functions (Tamarkin et al., 1985). When Exps I and II are compared, there is a similarity of birth distribution curves obtained with the daily shifts of light phase and the corresponding shifts of melatonin treatment. Nevertheless, melatonin seems less efficient than the entire light-dark cycle since, with a periodicity of $23: 45 \mathrm{~h}, 57.7 \%$ of the animals delivered on Day 23 when treated with melatonin and $83.0 \%$ exposed to this light regimen.

Several points arise with regard to the photoperiodic and melatonin responses observed in the two experiments, in particular the variations of birth rate on Days 22 and 23 of pregnancy and the cessation in parturitions which separates those observed on these two days. These differences may be explained by the incompatibility which exists between birth and the main daily activity (Bosc et $a l ., 1986)$ and by the entrainment of the latter by the light regimen or by melatonin (Armstrong \& Redman, 1985). Pregnant rats fed ad libitum are normally active during darkness (Bosc et al., 1986) which corresponds to the nocturnal break in parturitions illustrated by the control groups in the two experiments. As birth cannot be initiated before a given time (12:00 h of Day 22 of gestation in our conditions) it occurs more frequently on Day 22 or on Day 23 depending on whether the daily activity is situated at the beginning of the day or at its end (Bosc et al., 1986). In Exp. I, the shifts of light phase have certainly entrained the daily nocturnal activity according to observations made under similar conditions (M. J. Bosc, unpublished). The delay of activity due to the periodicity of 24:15 h has therefore allowed more deliveries to occur before lights off on Day 22, and the advance of activity with the periodicity of $23: 45 \mathrm{~h}$ has delayed most births until after lights on, on Day 23; the intermediate situation is represented here by the control group (Fig. 1). Under dim constant light conditions, the period of circadian activity averages $24: 30 \mathrm{~h}$ (Cheung \& McCormack, 1982). Theoretically, therefore the rats should have delivered primarily on Day 22 as the consequence of the delay in activity expected after 2 weeks of such a regimen. In Exp. II, the rates of birth observed on Day 22 in untreated animals (Group LL), in vehicle control groups (Groups V, BV and FV) and in groups receiving melatonin with periodicities of 24:00 h and 24:15 h (Groups $M$ and FM) support this interpretation.

Whether the present findings are pharmacological or physiological remains an open question, but some observations can be made about the properties of melatonin in regard to birth. Under normal conditions, birth is rarely observed during darkness (Bosc, 1981) when melatonin is secreted (Ozaki et al., 1976; Wilkinson et al., 1977; Adler et al., 1979; Illnerova \& Vanêcék, 1980; Ho et al., 1984). In our experiments, no toxic effects have been noted for the dams and their litters as has been reported for melatonin implants in rats (Tigghelaar \& Nalbandov, 1975; Nir \& Hirschmann, 1982). With melatonin implants, which gave a constant release of the hormone (Murakami et al., 1983), a significant reduction in length of gestation has been observed (Nir \& Hirschmann, 1980), as found here but to a lesser extent in rats in Groups $M$ and FM compared with those in Groups V and FV. In rats in Group BM, melatonin has produced an increase in gestation length. These two types of responses suggest that the clearance of the molecule is sufficiently rapid as to give different effects depending on the time of administration.

Melatonin may be involved in the endocrine control of parturition at several points (see 'Introduction'). However, its role in the control of these photoperiod-dependent functions such as seasonal breeding appears to be that of a synchronizer acting on central nervous rhythm-generating systems (Tamarkin et al., 1985). Our results suggest that melatonin secretion may be a mechanism whereby photoperiod regulates the time of parturition in the rat. Its site of action remains to be elucidated.

I thank Mrs A. Nicolle and D. Ducelliez for valuable help with the treatments, and Mr C. Cahier, Mr M. Pellan and Mr M. Vigneau for animal care. 


\section{References}

Adler, J., Lynch, H.J. \& Wurtman, R.J. (1979) Effects of cyclic changes in environmental lighting and ambient temperature on the daily rhythms in melatonin excretion by rats. Brain Res. 163, 111-120.

Armstrong, S.M. \& Redman, J. (1985) Melatonin administration: Effects on rodent circadian rhythm. In Photoperiodism, Melatonin and the Pineal (Ciba Fdn Symp No. 117), pp. 188-202. Pitman, London.

Bosc, M.J. (1981) Effects of photoperiod on the time of birth in the rat. In Photoperiodism and Reproduction in Vertebrates, pp. 39-50. Eds R. Ortavant, J. Pelletier \& J. P. Ravault. INRA, Versailles.

Bosc, M.J. \& Nicolle, A. (1979) Effect of stress on the course of labor and parturition time in normal or adrenalectomized rats. Annls Biol. anim. Biochim. Biophys. 19, 31-44.

Bosc, M.J. \& Nicolle, A. (1980) Influence of photoperiod on the time of parturition in the rat. I. Effect of length of daily illumination on normal or adrenalectomized animals. Reprod. Nutr. Dévelop. 20, 735-745.

Bosc, M.J., Nicolle, A. \& Ducelliez, D. (1986) Time of birth and daily activity mediated by feeding rhythms in the pregnant rat. Reprod. Nutr. Dévelop. 26, 777-789.

Cheung, P.W. \& McCormack, C.E. (1982) Failure of pinealectomy or melatonin to alter circadian activity rhythm of the rat. Am. J. Physiol. R261-R264.

Daya, S. \& Joubert, P.H. (1984) Glucocorticoid reversal of cyclic AMP down regulation in the rat pineal gland. IRCS Med. Sci. 12, 1057.

Gordon, W.L. \& Sherwood, O.D. (1982) Evidence that luteinizing hormone from the maternal pituitary gland may promote antepartum release of relaxin, luteolysis and birth in rats. Endocrinology 111, 1299 1310.

Ho, A.K., Grota, L.J. \& Brown, G.M. (1984) Relationship between pineal, $\mathbf{N}$ acetyltransferase activity, pineal melatonin and serum melatonin in rats under different lighting conditions. Neuroendocrinology 39, 465-470.

Illnerova, H. \& Vanêcék, J. (1980) Pineal rhythm in Nacetyltransferase activity in rats under different artificial photoperiods and in natural daylight in the course of a year. Neuroendocrinology 31, 321-326.

Mitchell, J.A. \& Yochim, J.M. (1970) Influence of environmental lighting on duration of pregnancy in the rat. Endocrinology 87, 472-480.
Murakami, N., Hayafuji, C., Sasaki, Y., Yamazaki, J. \& Takahashi, K. (1983) Melatonin accelerates the reentrainment of the circadian adrenocortical rhythm in inverted illumination cycle. Neuroendocrinology 36, 385-391.

Nir, I. \& Hirschmann, N. (1980) Melatonin induced changes in blood and pituitary luteinizing hormone and prolactin levels during the perinatal period in rats dams. J. neural Transmission 49, 219-228.

Nir, I. \& Hirschmann, N. (1982) Darkness elicited changes in rat reproduction not mediated by pineal gland. Hormone Res. 16, 385-391.

Ogle, T.F. \& Kitay, J.I. (1978) In vitro effects of melatonin and serotonin on adrenal steroidogenesis. Proc. Soc. exp. Biol. Med. 157, 103-105.

Ozaki, Y., Lynch, H.J. \& Wurtman, R.J. (1976) Melatonin in rat pineal plasma and urine $24 \mathrm{~h}$ rhythmicity and effect of chlorpromazine. Endocrinology 98, 1418-1424.

Tamarkin, L., Baird, C.J. \& Almeida, O.F.X. (1985) Melatonin: a coordinating signal for mammalian reproduction? Science, $N . Y .227,714-720$.

Tigghelaar, P.V. \& Nalbandov, A.V. (1975) The effect of the pineal gland on ovulation and pregnancy in the rat. Biol. Reprod. 13, 461-469.

Vessereau, A. (1960) Methodes statistiques en biologie et agronomie. In Recherches et Expérimentation en Agriculture, p. 532. Eds F. Boeuf \& A. Vessereau, J. B. Baillères et Fils, Paris.

Wilkinson, M., Arendt, J., Bradtke, J. \& de Ziegler, D. (1977) Determination of a dark-induced increase of pineal $\mathrm{N}$-acetyltransferase activity and simultaneous radioimmunoassay of melatonin in pineal, serum and pituitary tissue of the male rat. J. Endocr. 72, 243-244.

Wong, D.L., Hayashi, R.J. \& Ciaranello, R.D. (1985) Regulation of biogenic amine methyltransferase by glucocorticoids via S-adenosylmethionine and its metabolizing enzymes, methionine adenosyltransferase and S-adenosylhomocysteine hydrolase. Brain Res. 330, 209-216. 